\title{
Comparing Plant Species Diversity in Different Altitudinal Zones of Bolikhamxay Province, Central Lao PDR
}

\author{
Pan Noymany ${ }^{1}$, Anoulom Vilayphone ${ }^{1}$, Viengsamone \\ Thammavong ${ }^{1}$, Soukkongseng Saingaleuth ${ }^{1}$, Houngphet \\ Chanthavong ${ }^{1}$
}

\author{
${ }^{1}$ Faculty of Forest Science, National University of Lao PDR (NUOL), P.O.Box: 7322, Vientiane, Lao PDR
}

\begin{abstract}
The paper aims to examine plant species diversity, density, and distribution in different altitudinal zones of Bolikhamxay Province, Central Lao PDR. We conducted an inventory to collect the data from a total of 10 sampling plots from five villages of four districts of Bolikhamxay Province situated at different geographical locations with different above mean sea level. The analysis revealed that the Shannon diversity index was diverse in all sites. We found approximately 55 plant species with circumference of greater than $94 \mathrm{~cm}$ in the sampling plot 40x40 $\mathrm{m}$ and 43 plant species with circumference of $32-93 \mathrm{~cm}$ in the sampling plot $20 \times 20 \mathrm{~m}$. We also found 40 different plant species in the sampling plot $10 \times 10 \mathrm{~m}$ when tree species has circumference of $4-31 \mathrm{~cm}$. In small sampling plots $2 \times 2 \mathrm{~m}$, we found 43 plant species which are plant species with circumference of less than $3 \mathrm{~cm}$ (height of $0.3-1.5 \mathrm{~m}$ ) and non-timber forest products (NTFPs). Overall, there were high variations in relative density, density, species richness, litter decomposition, and soil hardness in the study area and it can be concluded that the study area has diverse plants species and different geographical habitats of trees.
\end{abstract}

\section{Introduction}

Indo-Burma region is one of the biodiversity hotspots where about 13,500 vascular plants species were scientifically found. Of these, approximately 7,000 plants or $52 \%$ identified are currently endemic (Mittermeier, Robles-Gil et al. 2004). Lao PDR (in short Laos) is located at the centre of this biodiversity hotspot, which is very rich in biologically fertile for both plants and animals. In Laos, about 5,005 species in 1,373 genera and 188 families of native seed plants were found. Families consist of more than 100 species include Fabaceae (100 genera / 521 species), Orchidaceae (96 /506), Euphorbiaceae (48/231), Rubiaceae (64/229), Poaceae (78/177), Lamiaceae (38/149), Cyperaceae (19/114), Fagaceae (4/109), Moraceae (7/108), Asteraceae (59/180), and Zingiberaceae (15/104) (Zhu 2017). There is an increasing new discovery of new plant species over the past few decades. For instance, Tagane, et al. (2018) has recently discovered thirty angiosperm species in 20 families, collected in Nam Kading National Protected Area, Central Laos.

However, over the past century, Laos has observed a rapid decrease in its natural forest. According to the most recent record by the Lao Department of Forestry (DOF), the total area of the forest decreased dramatically from $70 \%$ of the land area or approximately 17 million hectares in 1940 , to 11.6 million hectares in 1982, and to only $41 \%$ (about 9.8 million hectares) in 2002 (Phimmavong, Ozarska et al. 2009) but managed to increase to $58 \%$ in 2015. Many endemic plant species are threatened by recent human activities namely industrial plantation, logging, mining, the construction of roads and hydropower and agricultural activities. Such development activities bring about negative impact on the natural habitat of fauna and flora in Laos.

The government of Laos has a strong policy in place to conserve its remaining biodiversity. For instance, one of the key government policies is the National Biodiversity Strategy to 2020 and Action Plan to 2010 which indicates that the conservation of the national biodiversity plays an important role in reducing poverty as more than $80 \%$ of the Lao population live in rural areas where most forest are located.

Over the past couple of decades, several studies have been carried out on plant diversity of different part of the world (Devi and Behera 2003; Stanisci, Pelino et al. 2005; Hayat, Kudus et al. 2010; Dalmayne, Möckel et al. 2013; Peng, Fan et al. 2018). 
To date, very few researches in Laos has been undertaken to assess plant species diversity especially the assessment of plant species richness, its density, leave little composition, and soil hardness. Most plant surveys efforts in Laos over the past few decades have paid only attention on the national system of large forest National Protected Areas (NPAs), while comprehensive studies in species richness of tree species remain very few or insufficient knowledge.

This paper aims to assess plant species diversity in different altitudinal zones of Bolikhamxay Province, Central Lao PDR. The specific objectives of the study are as follows.

- Assess species richness of plants, more precisely trees and non-timber forest products (NTFPs) in different altitudinal zones of Bolikhamxay Province

- Determine the density of plant and NTFPs in the study area, and

- To quantify the plant leaves biomass and conduct soil hardness measurement

\section{Methods}

\subsection{Study area}

The current study was conducted in five villages of four districts of Bolikhamxay Province (Figure 1). The study area has different geographical location with different above mean sea level namely Pakxoum Village (Pakkading District) with 150-200 meters above sea level, Kenyong (Bolikhan District) with 300-400 meters above sea level, Muangmouan village (Viengthong District) with 400-500 meters above sea level, Phontan (Khamkeut District) with 500-600 meters above sea level and Napae village (Khamkeuth District) with of 600-700 meters above sea level.

There are two sampling plots per one village with the total of 10 sampling plots for the current study. Each sampling plot is $40 \times 40$ meter. For each sampling plot, sub-plots were located at the corner of each plot with different size of $20 \times 20$ meter, $10 \times 10$ meter, $2 \times 2$ meter, and 1x1 meter. The purpose of sub-plot establishment is described as follows.

1) Sampling plot $40 \times 40 \mathrm{~m}$ are designed to collect data of all trees with circumference of greater than 94 centimetre $(\mathrm{cm})$.

2) Sampling plot $20 \times 20 \mathrm{~m}$ is designed to collect tree information with circumference of $32-93 \mathrm{~cm}$.

3) Sampling plot $10 \times 10 \mathrm{~m}$ is designed to collect tree information with circumference of 4-31, tree height with greater than 1.5 meter and small plants.

4) Sampling plot $2 \times 2 \mathrm{~m}$ is designed to collect tree data with circumference of less than $3 \mathrm{~cm}$ and height with $0.3-1.5$ meter

5) Sampling plot $1 \times 1 \mathrm{~m}$ is planned to collect data of biomass: branches, twig, dry and green leaves and grass

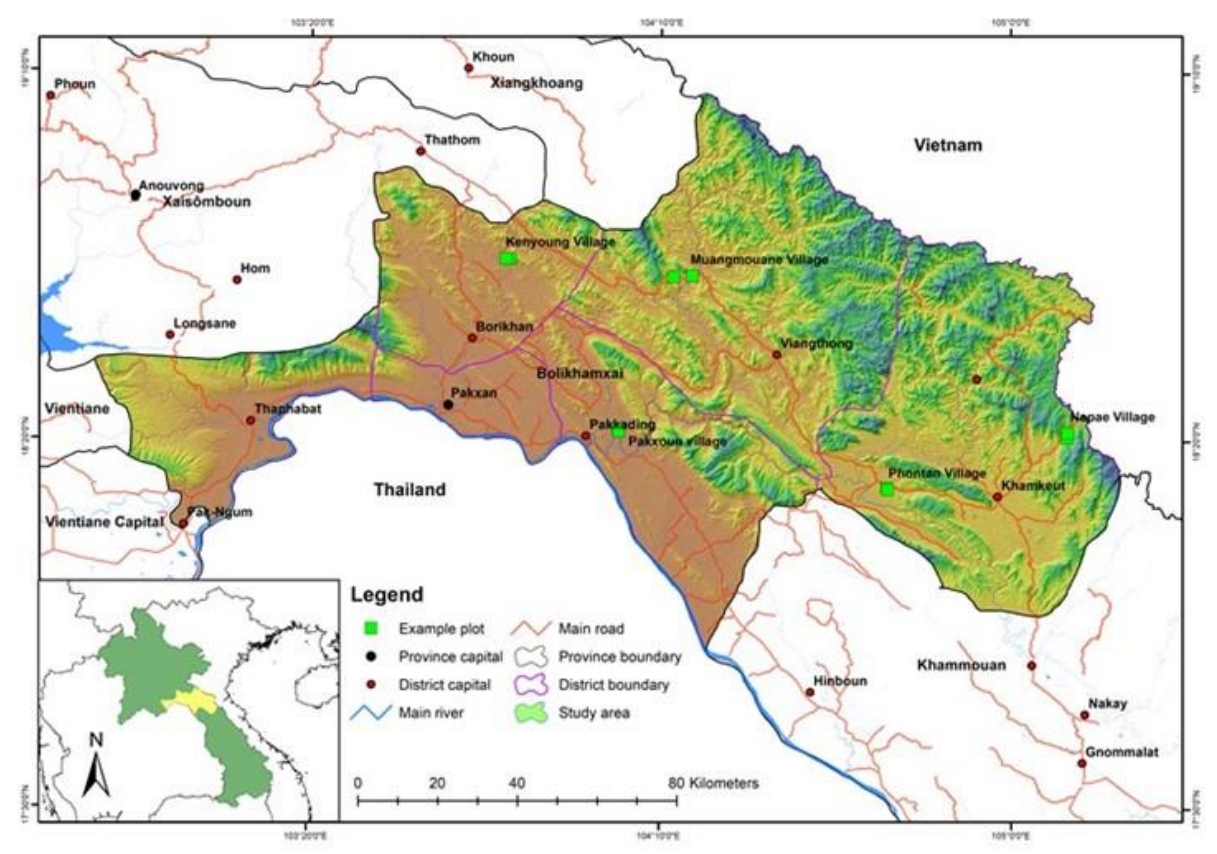

Figure 1: Map of distribution of sampling plots in Bolikhamxay Province

Forest Characteristics of the study area
The vegetation types and plant species surveyed in this study are situated in different altitudinal gradient 
Table 1: Characteristics of sampling plots

\begin{tabular}{|c|c|c|c|c|c|c|c|c|}
\hline No. & Location & $\begin{array}{l}\text { Plot } \\
\text { ID }\end{array}$ & \multicolumn{2}{|c|}{ Coordinates } & Elevation & Forest type & $\begin{array}{c}\text { Slope } \\
\text { (degrees) }\end{array}$ & Forest health \\
\hline \multirow{2}{*}{1} & \multirow{2}{*}{ Pakxoun village } & A1 & $X: 401363$ & $Y: 2030510$ & $176 \mathrm{~m}$ & $\begin{array}{l}\text { Semi- } \\
\text { evergreen }\end{array}$ & 15 & undisturbed \\
\hline & & $\mathrm{A} 2$ & $X: 401562$ & Y:2029884 & $158 \mathrm{~m}$ & Rehabilitated & $<5$ & disturbed \\
\hline \multirow{2}{*}{2} & \multirow{2}{*}{ Kenyong village } & $\mathrm{B} 1$ & $X: 374400$ & Y:2073809 & $320 \mathrm{~m}$ & evergreen & 11 & undisturbed \\
\hline & & $\mathrm{B} 2$ & $X: 373405$ & $Y: 2073150$ & $304 \mathrm{~m}$ & Secondary & $<5$ & disturbed \\
\hline \multirow{2}{*}{3} & \multirow{2}{*}{$\begin{array}{l}\text { Muangmouane } \\
\text { village }\end{array}$} & $\mathrm{C} 1$ & $X: 415407$ & Y:2068556 & $440 \mathrm{~m}$ & Evergreen & 5 & undisturbed \\
\hline & & $\mathrm{C} 2$ & $\mathrm{X}: 420140$ & Y:2068712 & $474 \mathrm{~m}$ & Secondary & 11 & disturbed \\
\hline \multirow[b]{2}{*}{4} & \multirow[b]{2}{*}{ Phontan village } & D1 & $X: 468724$ & Y:2015549 & $520 \mathrm{~m}$ & Evergreen & 20 & undisturbed \\
\hline & & $\mathrm{D} 2$ & $X: 469018$ & $Y: 2015158$ & $590 \mathrm{~m}$ & $\begin{array}{l}\text { Mixed } \\
\text { Deciduous }\end{array}$ & 23 & disturbed \\
\hline \multirow[b]{2}{*}{5} & \multirow[b]{2}{*}{ Napae village } & E1 & $X: 513965$ & Y:2028101 & $608 \mathrm{~m}$ & Evergreen & 25 & undisturbed \\
\hline & & E2 & $X: 514132$ & $Y: 2029288$ & $615 \mathrm{~m}$ & $\begin{array}{l}\text { Mixed } \\
\text { Deciduous }\end{array}$ & 21 & disturbed \\
\hline
\end{tabular}

Source: Fieldwork, 2014

\subsection{Data collection}

The following data from the sampling plots of

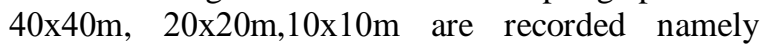
species name, diameter at breast height (dbh), total height, small shrubs. For quadrate $2 \times 2$ meter, we recorded data on NTFPs and plant species with circumference of $3 \mathrm{~cm}$ and height of 0.3 to 1.5 meter. For the quadrate $1 \times 1$ meter, we collected biomass data namely twig, branches, dry and green leaves and grass. Figures 2-3 showed measurement of trees in sampling plots.

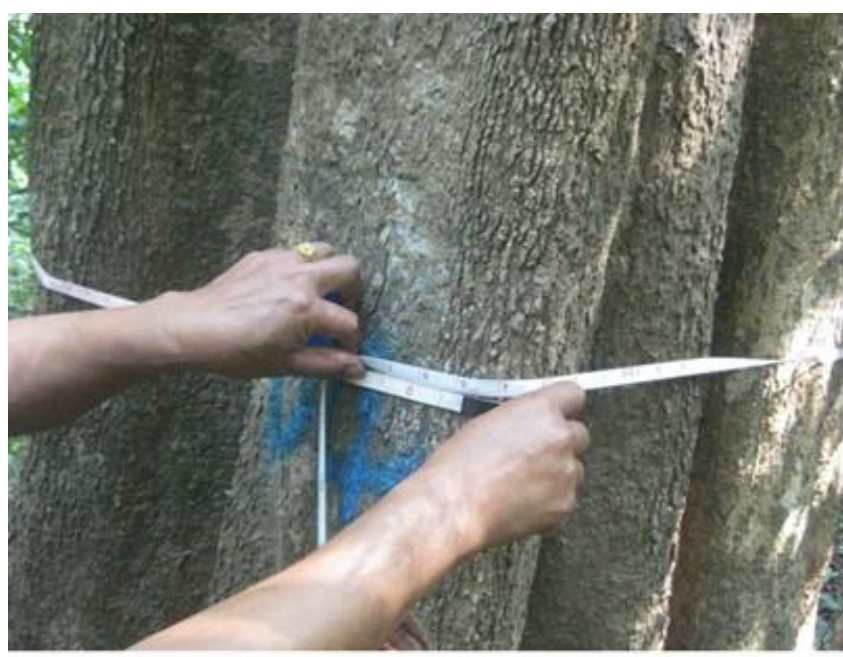

Figure 2: Survey and measurement of trees species

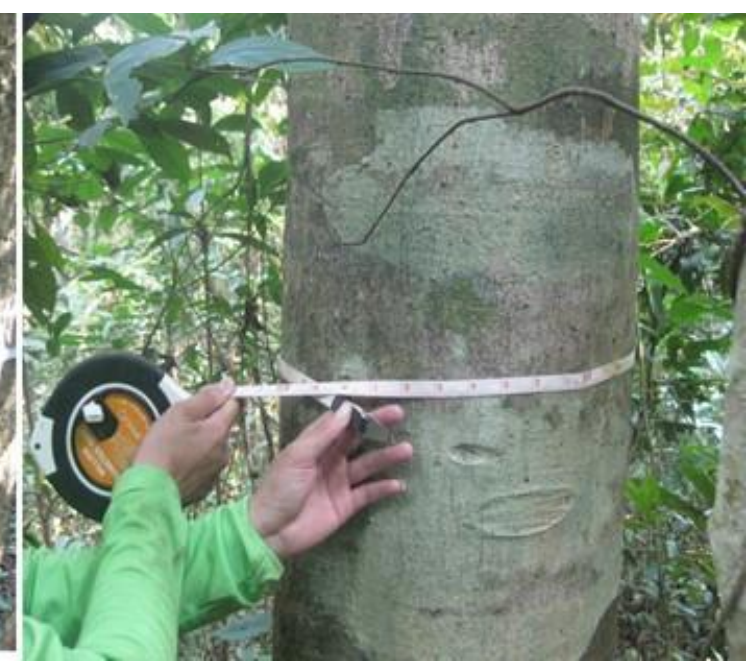



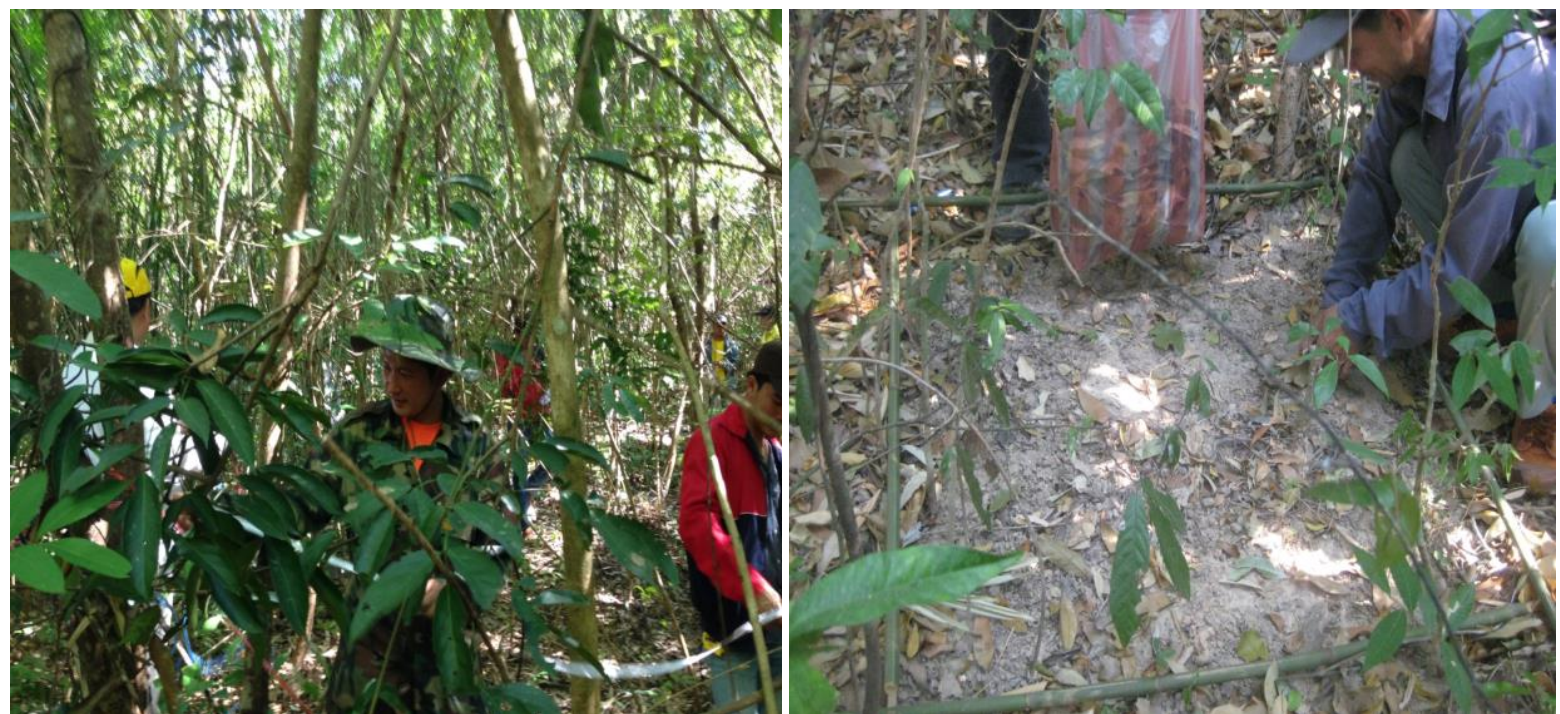

Figure 3: Survey and measurement of NTFPS, branches, leaves and grass

For the sampling plot $40 \times 40 \mathrm{~m}$, the total number of tree species with circumference of greater than $94 \mathrm{~cm}$ was 55 plant species. Of these, 12 plant species were found in Pakxoum village with altitude ranges from 150-200 meters above sea level while Kenyong village located at the altitude ranges of 300-400 meters above sea level witnessed 7 plant species. In Muangmouane village which has the sea altitude ranges of 400-500 meters above sea level, 16 plant species were found while Phontan village with altitude ranges 500-600 meters above sea level, 19 plant species were identified and Napae Village, 27 plant species were identified.

The most dominant plant species are Quercus macrocalyx Hickel \& A.Cam, Rhaphiolepis indica (L.) Lindl.ex Ken, Ormosia cambodiana Gagnep, Streblus ilicifolius (J.E vidal) corner, Parashorea Stellata Kurz, Dysoxylum excelsum Blume, Croton joufra Roxb, Dysoxylum loureiri Pierre, Vitex glabrata $\mathrm{R} . \mathrm{Br}$ respectively (Figure 4). 


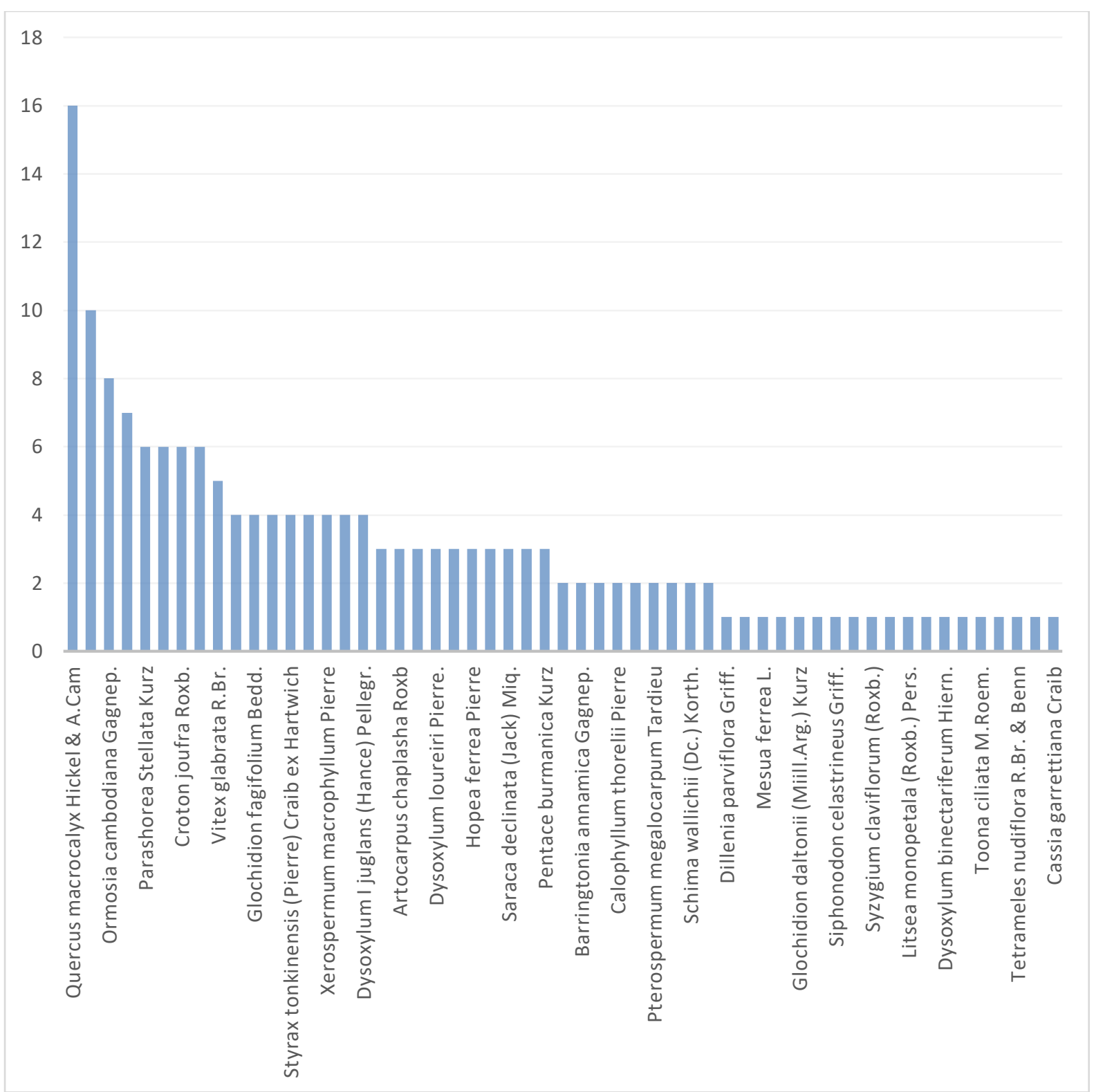

Figure 4: Distribution of trees in the sampling plot 40x40m

Similarly, from the analysis of the sampling plot $20 \times 20 \mathrm{~m}$, the total number of tree species with circumference of $32-93 \mathrm{~cm}$ is 43 plant species. Of these, 23 species were found in Pakxoum village with altitude ranges of 150-200 meters while Kenyong village located at the altitude ranges of $300-400$ meters witnessed a 12-plant species. In Muangmouane village which has the sea altitude ranges of 400-500 meters, 12 plant species were found while Phontan village with altitude ranges 500-
600 meters, 18 plant species were identified and Napae Village, 16 plant species were identified.

The most dominant plant species are Dysoxylum binectariferum Hicrn., Quercus macrocalyx Hickel \& A.Cam, Streblus ilicifolius (J.E vidal) corner, Cratoxylum formosum (Jack) Dyer, Croton joufra Roxb., Cassia garrettiana Craib, Ormosia cambodiana Gagnep, Xerospermum laoticum Gagnep, Croton crassifolus Geiseler, Pterospermum megalocarpum Tardieu respectively (Figure 5). 


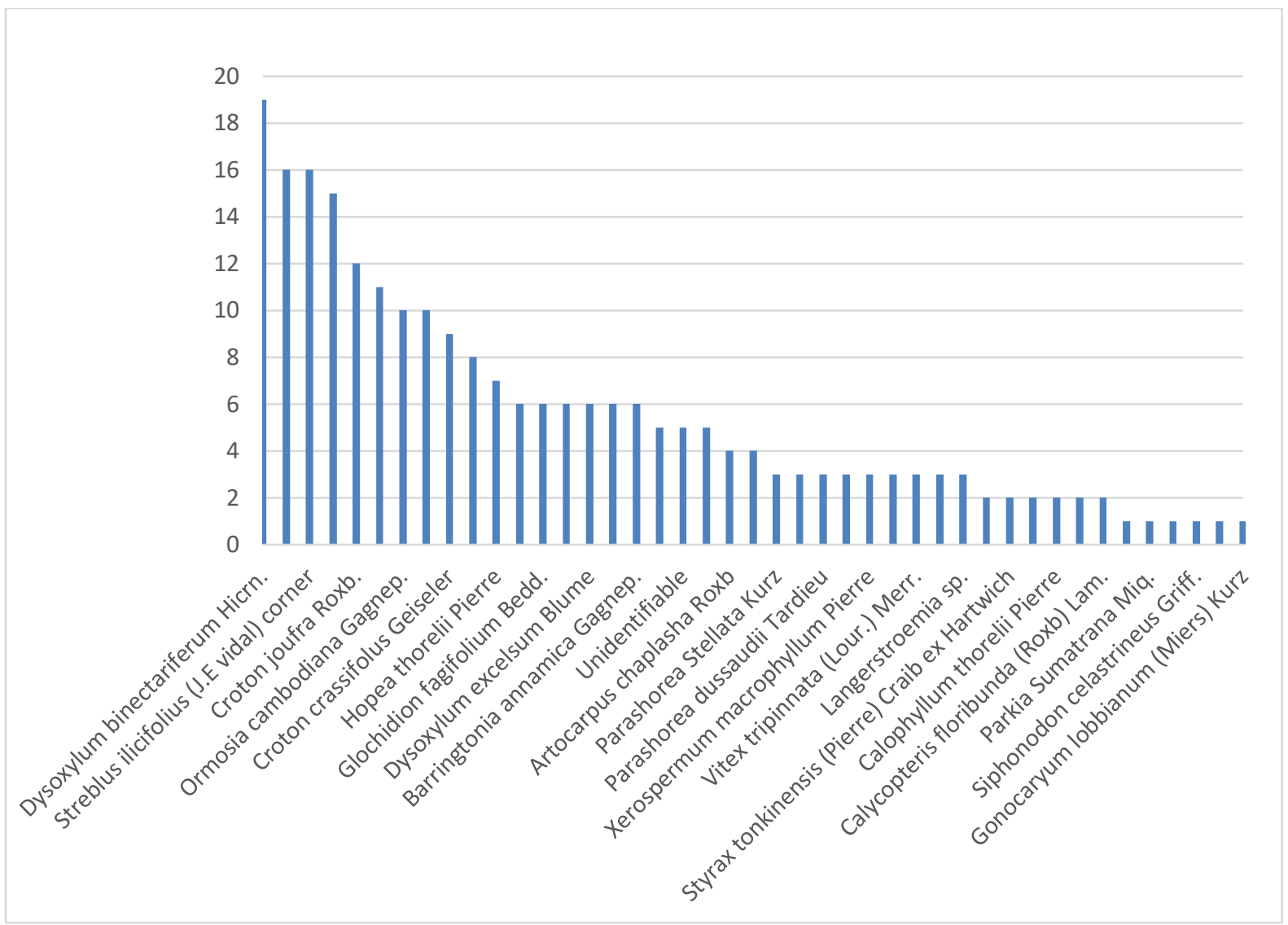

Figure 5: Distribution of trees in the sampling plot 20x20m

For the sampling plot $10 \times 10$ meter, the total number of tree species with circumference of $4-31 \mathrm{~cm}$ is 40 plant species. Of these, 19 species were found in Pakxoum village with altitude ranges of $150-200 \mathrm{~m}$ while Kenyong village located at the altitude ranges of $300-400 \mathrm{~m}$ witnessed 20 plant species. In Muangmouane village which has the altitude ranges of $400-500 \mathrm{~m}$ above the sea level, 17 plant species were found while Phontan village with altitude ranges $500-600 \mathrm{~m}, 30$ plant species were identified and Napae Village, 26 plant species were identified.
The most dominant plant species are Glochidion daltonii (Miill.Arg.) Kurz, Unidentifiable, Croton joufra Roxb, Quercus macrocalyx Hickel \& A.Cam, Ormosia cambodiana Gagnep, Cratoxylum formosum (Jack) Dyer, Dipterocarpus a tatus Roxb. ex E.Don, Millettia boniana Gagnep, Parashorea Stellata Kurz, Gonocaryum lobbianum (Miers) Kurz respectively (Figure 6). 


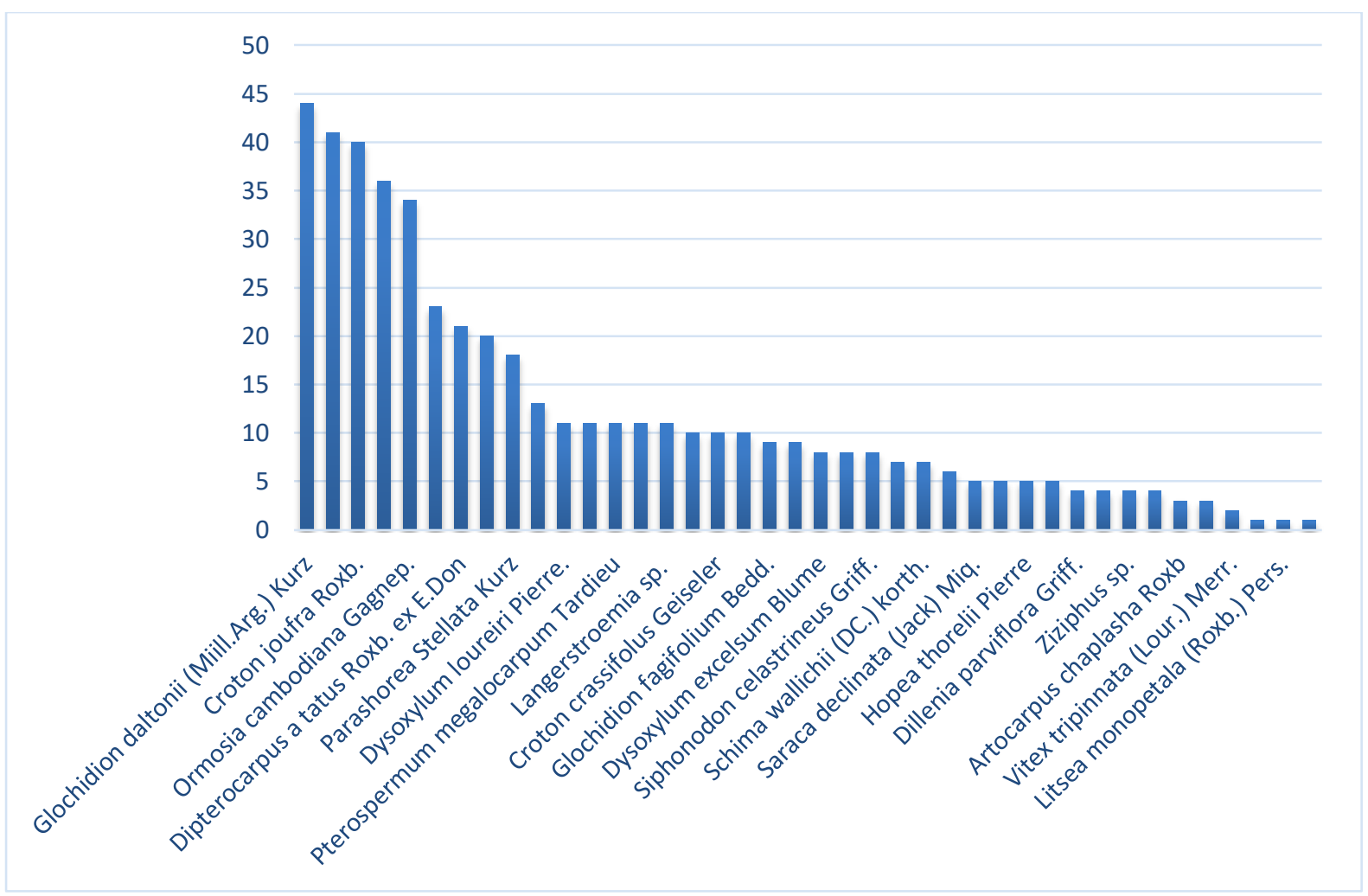

Figure 6: Distribution of trees in the sampling plot 10x10m

For the sampling plot $2 \times 2 \mathrm{~m}$, the total number of tree species with circumference of less than $3 \mathrm{~cm}$ (height of $0.3-1.5 \mathrm{~m})$ as well as the measurement of nontimber forest products (NTFPs) is 43 plant species. Of these, 10 tree species, 5 species of NTFPs and 190 shrubs were found in Pakxoum village with altitude ranges of 150-200 $\mathrm{m}$ while Kenyong village located at the altitude ranges of 300-400m witnessed 8 tree species, 7 species of NTFPs and 13 shrubs. In Muangmouane village which has the altitude ranges of 400-500m, 10 tree species, 8 species of NTFPs and 37 shrubs were found while Phontan village with altitude ranges of 500-600 m, 9 tree species, 6 species of NTFPs and 17 shrubs were identified and Napae Village, 6 tree species, 9 species of NTFPs and 205 clumps were identified.

The most dominant plant species are Pak Koud Dong and Ton san while the less dominant is maktao as shown in Figure 7. 


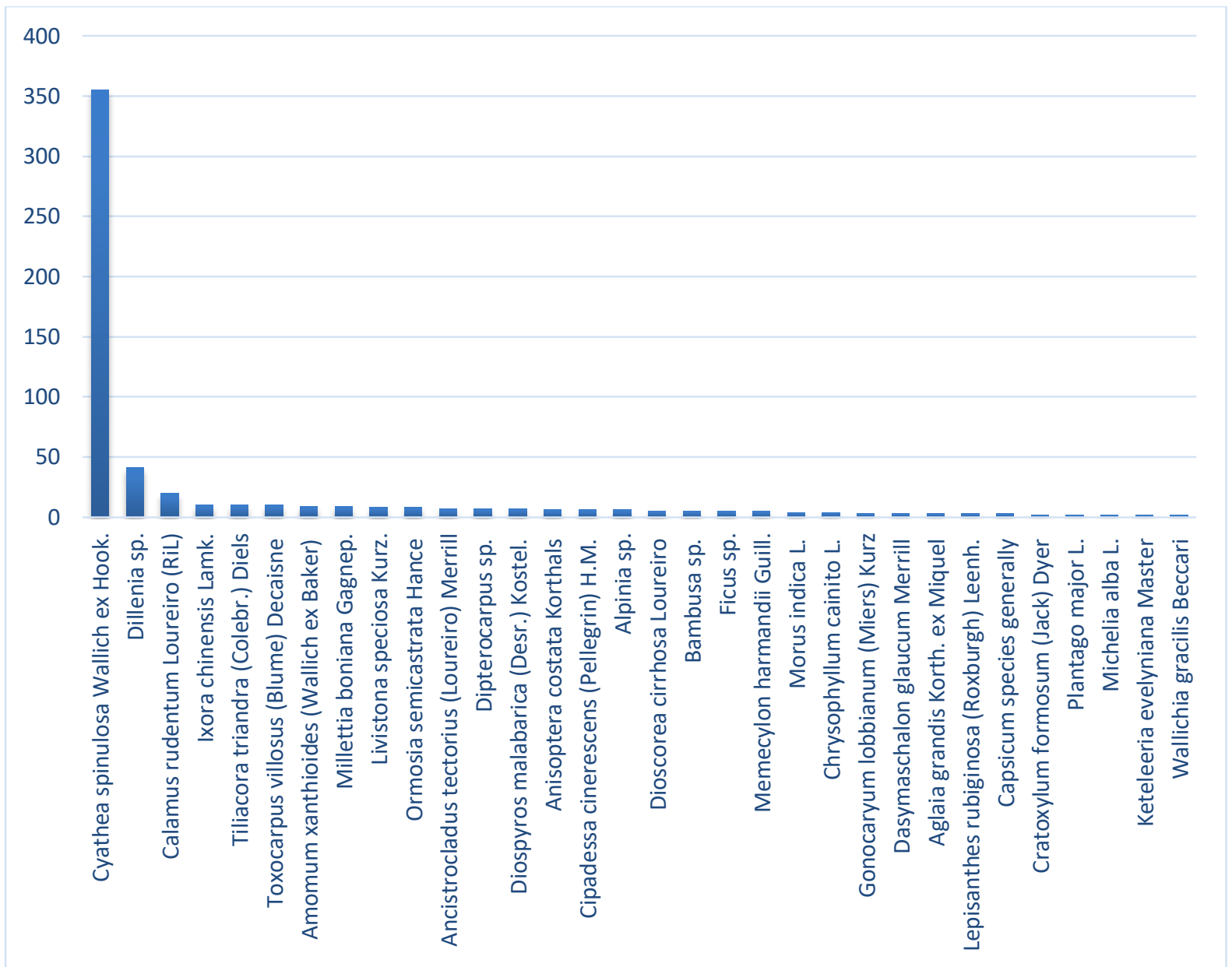

Figure 7: Distribution of trees in the sampling plot $2 \times 2 \mathrm{~m}$

\subsection{Species density and Richness}

To achieve the aim of the study, we employ three main equations to derive relative density, density, and species richness.

\section{A. Relative density}

We use the relative density which is the examination of numerical strength of a species regarding the total number of individuals of the all the species as written as follows.

Relative density $R D(\%)=\frac{n}{N} \times 100$

Where

$\mathrm{RD}$ refer to a relative density (\%) $\mathrm{n}$ refers to the number of individual

of the species

$\mathrm{N}$ refers to the number of individual of all the species

\section{B. Density of plants including NTFPS}

Density of plants is representation of the numberical strength of the species in which the total number of individuals of each species in all the quadrats is divided by the total number of quadrats investigated.

$$
d=\frac{N}{a}
$$

where

$\mathrm{d}$ is density of plants including NTFPs $a$ the number of quadrats investigated

$\mathrm{N}$ : Total number of individuals of a species in all quadrats

C. Species richness is a simple count of species whereas species evenness quantifies how equal the abundance of the species (Kent and Coker 1992). Species richness $(\mathrm{R})$ is a common indicator to measure biodiversity or and a count of the number of different species in a sampling plot. In this study, we employed the Margalef diversity index which is written in a spreadsheet:

$$
\begin{aligned}
& R=\frac{S-1}{\ln (N)} \\
& \text { R: Species richness } \\
& \text { S: Total number of species } \\
& \text { N: Total number of individuals }
\end{aligned}
$$

We calculated the percentage changes as the proportion of Margalef index determined with the 
density matrix divided by the Margalef index determined with the absolute numbers matrix.

When $R \geq 1$ this indicates that the areas have richness in biodiversity.

\subsection{Forest leaves and soil hardness measurement}

To measure the litter decomposition, we distinguished into dry and green litter from the forest and these dry and green leaves are weighted separately during the inventory.

To measure the soil hardness, we used the soil hardness tester. The tester employs a theoretical value of pressure gauge in Kilogram per $\mathrm{cm}^{2}$, directly measures soil hardness. The technique for soil hardness testing can be understood as follows.

First, we level the measuring soil surface, then insert top part of instrument into the soil until (opening) part. Then we vertically pull out the soil hardness meter and then seeing the hardness indicating value of the meter. After completing reading the measured value, drive rotary-knob, make the indicating meter to zero. It is important to note that the hardness indication range: $0-40 \mathrm{~mm}, 0-500 \mathrm{~kg} / \mathrm{cm}^{2}$.

\section{Results}

The result of the analysis for four main indicators of the plant richness: relative density of plant species, density of plants in areas sampled as well as assessment result of litter decomposition and soil strength are explained as follows.

\subsection{Relative density of plant species}

The analysis of relative density of tree species with circumference of greater than $94 \mathrm{~cm}$ was experimented in the sampling plot $40 \times 40 \mathrm{~m}$ which was called "RD1" while tree species with circumference of $32-93 \mathrm{~cm}$ in the sampling plot $20 \times 20$ $\mathrm{m}$ was called "RD2". RD3 is the sampling plot size of $10 \times 10 \mathrm{~m}$ which has tree circumference of $4-31 \mathrm{~cm}$ and RD4 is the sampling plot size of $2 \times 2 \mathrm{~m}$ which has tree size with circumference of less $3 \mathrm{~cm}$. The result of the analysis is reported in tables 2-5 respectively.

Table 2 displays the relative density of tree species of the sampling plot size $40 \times 40 \mathrm{~m}$ and it indicates that the lowest relative density is $0 \%$ in Kenyong village while the highest relative density is $75.0 \%$ which is in the sampling plot zone three in Mouangmouan Village.

Table 2: Relative density of the tree species in the sampling plot size $40 \times 40 \mathrm{~m}$

\begin{tabular}{|l|l|l|}
\hline \multicolumn{1}{|c|}{ Sampling plots } & Plot number & \multicolumn{1}{|c|}{ Relative Density/RD1 (\%) } \\
\hline Zone 1: Pakxoun Village, sea & $\mathrm{A} 1$ & $6.2 ; 12.5 ; 18.7$ \\
\cline { 2 - 3 } altitude ranges 150-200m & $\mathrm{A} 2$ & $33.3 ; 66.6$ \\
\hline Zone 2: Kenyong Village, sea & $\mathrm{B} 1$ & $11.1 ; 22.2$ \\
\cline { 2 - 3 } altitude ranges 300-400m & $\mathrm{B} 2$ & 00 \\
\hline $\begin{array}{l}\text { Zone 3: Muangmouane } \\
\text { Village, sea altitude ranges }\end{array}$ & $\mathrm{C} 1$ & $2.5 ; 5.0 ; 7.5 ; 10.0 ; 27.5$ \\
\cline { 2 - 3 } 400-500m & $\mathrm{C} 2$ & $25.0 ; 75.0$ \\
\hline $\begin{array}{l}\text { Zone 4: Phontan Village, sea } \\
\text { altitude ranges 500-600m }\end{array}$ & $\mathrm{D} 1$ & $2.8 ; 5.7 ; 11.4 ; 28.6$ \\
\cline { 2 - 3 } $\begin{array}{c}\text { Zone 5: Napae Village, sea } \\
\text { altitude ranges 600-700m }\end{array}$ & $\mathrm{D} 2$ & $16.6 ; 33.3$ \\
\cline { 2 - 3 } & $\mathrm{E} 1$ & $2.5 ; 5.0 ; 7.5 ; 15.0 ; 32.5$ \\
\hline
\end{tabular}

The relative density of the sampling plot size $20 \times 20$ $\mathrm{m}$ is showed in table 3 and the analysis result indicates that the lowest relative density is $13.0 \%$
(C1.1; RD2) in Muangmouane village while the highest $50.0 \%$ (D2.1; RD2) which is in the sampling plot zone four in Phontan Village.

Table 3: Relative density of tree species of the sampling plot size 20x20m

\begin{tabular}{|l|l|l|}
\hline Sampling plots & Plot number & \multicolumn{1}{|c|}{ Relative Density/RD2 (\%) } \\
\hline Zone 1: Pakxoun Village, sea & $\mathrm{A} 1.1$ & $5.9 ; 11.8 ; 17.6$ \\
\cline { 2 - 3 } altitude ranges from150-200m & $\mathrm{A} 2.1$ & $2.7 ; 5.4 ; 8.1 ; 10.8 ; 27.0$ \\
\hline Zone 2: Kenyong Village, sea & $\mathrm{B} 1.1$ & $4.3 ; 8.7 ; 13.0 ; 17.4 ; 34.8 ; 47.8$ \\
\cline { 2 - 3 } altitude ranges from 300-400m & $\mathrm{B} 2.1$ & $14.3 ; 42.9$ \\
\hline Zone 3: Muangmouane Village, sea & $\mathrm{C} 1.1$ & $4.3 ; 8.7 ; 13.0$ \\
\cline { 2 - 3 } altitude ranges from 400-500m & $\mathrm{C} 2.1$ & $2.8 ; 5.6 ; 13.9 ; 25.0 ; 41.7$ \\
\hline Zone 4: Phontan Village, sea & $\mathrm{D} 1.1$ & $3.6 ; 7.1 ; 10.7 ; 17.9$ \\
\hline altitude ranges from 500-600m & $\mathrm{D} 2.1$ & $12.5 ; 50.0$ \\
\hline Zone 5: Napae Village, sea altitude & $\mathrm{E} 1.1$ & $7.1 ; 14.3 ; 28.6$ \\
\cline { 2 - 3 } ranges from 600-700m & $\mathrm{E} 2.1$ & $3.4 ; 6.9 ; 10.3 ; 17.2$ \\
\hline
\end{tabular}


Table 4 displays the relative density of tree species of the sampling plot size $10 \times 10 \mathrm{~m}$ and the analysis result indicates that the lowest relative density is $8.6 \%$ in Phontan Village, with sea altitude ranges from 500-600 $\mathrm{m}$ while the highest relative density is $35.3 \%$ which is in the sampling plot zone five in Napae village.

Table 4: Relative density of tree species of the sampling plot size 10x10m

\begin{tabular}{|c|c|c|}
\hline Sampling plots & Plot number & Relative Density/RD3 (\%) \\
\hline \multirow{2}{*}{$\begin{array}{l}\text { Zone 1: Pakxoun Village, sea } \\
\text { altitude ranges from } 150-200 \mathrm{~m}\end{array}$} & A1.2 & $4.8 ; 9.5 ; 14.3$ \\
\hline & $\mathrm{A} 2.2$ & $3.3 ; 6.7 ; 10.0 ; 13.3$ \\
\hline \multirow{2}{*}{$\begin{array}{l}\text { Zone } 2 \text { : Kenyong Village, sea } \\
\text { altitude ranges from } 300-400 \mathrm{~m}\end{array}$} & $\mathrm{~B} 1.2$ & $2.1 ; 4.2 ; 6.3 ; 8.3 ; 14.6 ; 31.3$ \\
\hline & $\mathrm{B} 2.2$ & $1.4 ; 2.9 ; 4.3 ; 7.2 ; 8.7 ; 10.1 ; 18.8 ; 31.9$ \\
\hline \multirow{2}{*}{$\begin{array}{l}\text { Zone 3: Muangmouane Village, sea } \\
\text { altitude ranges from } 400-500 \mathrm{~m}\end{array}$} & $\mathrm{C} 1.2$ & $4.3 ; 8.7 ; 13.0$ \\
\hline & $\mathrm{C} 2.2$ & $1.2 ; 4.7 ; 5.9 ; 7.1 ; 12.9 ; 14.1 ; 23.5 ; 30.6$ \\
\hline \multirow{2}{*}{$\begin{array}{l}\text { Zone 4: Phontan Village, sea } \\
\text { altitude ranges from } 500-600 \mathrm{~m}\end{array}$} & D1.2 & $1.7 ; 3.4 ; 5.2 ; 6.9 ; 8.6$ \\
\hline & D2.2 & $2.2 ; 4.4 ; 6.7 ; 8.9 ; 13.3 ; 22.2$ \\
\hline \multirow{2}{*}{$\begin{array}{l}\text { Zone 5: Napae Village, sea altitude } \\
\text { ranges from } 600-700 \mathrm{~m}\end{array}$} & E1.2 & $2.0 ; 3.9 ; 5.9 ; 7.8 ; 11.8 ; 35.3$ \\
\hline & E2.2 & $1.7 ; 3.4 ; 5.2 ; 6.9 ; 15.5 ; 19.0$ \\
\hline
\end{tabular}

Table 5 displays the relative density of plants and non-timber forest product of the sampling plot size $2 \times 2 \mathrm{~m}$ and the analysis result indicates that the lowest relative density is $22.2 \%$ in Kenyong Village, with sea altitude ranges from $300-400 \mathrm{~m}$ while the highest relative density is $89.4 \%$ which is in the sampling plot zone one in Paxoun village.

Table 5: relative density of plants of the sampling plot size $2 \times 2 \mathrm{~m}$

\begin{tabular}{|c|c|c|}
\hline Sampling plots & $\begin{array}{c}\text { Plot } \\
\text { number }\end{array}$ & Relative Density/RD4 (\%) \\
\hline \multirow{2}{*}{$\begin{array}{l}\text { Zone 1: Pakxoun Village, sea } \\
\text { altitude ranges from } 150-200 \mathrm{~m}\end{array}$} & A1.3 & $0.5 ; 1.1 ; 3.2 ; 4.3$ and 89.4 \\
\hline & A2.3 & $1.6 ; 3.3 ; 4.9 ; 6.6 ; 8.2$ and 67.2 \\
\hline \multirow{2}{*}{$\begin{array}{l}\text { Zone } 2 \text { : Kenyong Village, sea } \\
\text { altitude ranges from } 300-400 \mathrm{~m}\end{array}$} & $\mathrm{~B} 1.3$ & $7.7 ; 15.4$ and 23.1 \\
\hline & $\mathrm{B} 2.3$ & 11.1 and 22.2 \\
\hline \multirow{2}{*}{$\begin{array}{l}\text { Zone 3: Muangmouane Village, sea } \\
\text { altitude ranges } 400-500 \mathrm{~m}\end{array}$} & $\mathrm{C} 1.3$ & $3.7 ; 7.4 ; 14.8$ and 25.9 \\
\hline & $\mathrm{C} 2.3$ & $3.3 ; 10.0 ; 26.7$ and 36.7 \\
\hline \multirow{2}{*}{$\begin{array}{l}\text { Zone 4: Phontan Village, sea } \\
\text { altitude ranges from } 500-600 \mathrm{~m}\end{array}$} & D1.3 & $9.1 ; 18.2$ and 27.3 \\
\hline & D2.3 & $4.8 ; 9.5 ; 14.3 ; 19.0 ; 23.8 ; 28.6 ; 42.9$ and 47.6 \\
\hline \multirow{2}{*}{$\begin{array}{l}\text { Zone 5: Napae Village, sea altitude } \\
\text { ranges from } 600-700 \mathrm{~m}\end{array}$} & E1.3 & $3.7 ; 7.4 ; 14.8 ; 22.2$ and 48.1 \\
\hline & E2.3 & $0.5 ; 1.0 ; 1.5 ; 3.1 ; 3.6$ and 88.2 \\
\hline
\end{tabular}

\subsection{Density of plant and non-timber forest products in the study area}

The analysis on density of plants and non-timber forest products in the sampling plot of $2 \times 2 \mathrm{~m}$ by using relative density are shown in table 6 below.
The analysis result indicates that the lowest density is $2.3 \%$ in Kenyong Village, sea altitude ranges from $300-400 \mathrm{~m}$ while the highest relative density is $48.8 \%$ which is in the sampling plot zone five in Napae village.

Table 6: density of plant and non-timber forest products in the sampling plot of $2 \times 2 \mathrm{~m}$

\begin{tabular}{|c|c|c|}
\hline Sampling plots & $\begin{array}{c}\text { Plot } \\
\text { number }\end{array}$ & $\begin{array}{l}\mathrm{d}=\text { density of plant and non-timber forest product } \\
\text { per area }\left(\mathrm{d} / \mathrm{m}^{2}\right)\end{array}$ \\
\hline \multirow{2}{*}{$\begin{array}{l}\text { Zone 1: Pakxoun Village, sea } \\
\text { altitude ranges from } 150-200 \mathrm{~m}\end{array}$} & $\mathrm{~A} 1.3$ & 47.0 \\
\hline & A2.3 & 15.3 \\
\hline \multirow{2}{*}{$\begin{array}{l}\text { Zone } 2 \text { : Kenyong Village, sea } \\
\text { altitude ranges from } 300-400 \mathrm{~m}\end{array}$} & B1.3 & 3.3 \\
\hline & B2.3 & 2.3 \\
\hline \multirow{2}{*}{$\begin{array}{l}\text { Zone 3: Muangmouane Village, } \\
\text { sea altitude ranges from 400- } \\
500 \mathrm{~m}\end{array}$} & $\mathrm{C} 1.3$ & 6.8 \\
\hline & $\mathrm{C} 2.3$ & 7.5 \\
\hline \multirow{2}{*}{$\begin{array}{l}\text { Zone 4: Phontan Village, sea } \\
\text { altitude ranges from 500-600m }\end{array}$} & D1.3 & 2.8 \\
\hline & D2.3 & 5.3 \\
\hline \multirow{2}{*}{$\begin{array}{l}\text { Zone 5: Napae Village, sea } \\
\text { altitude ranges from } 600-700 \mathrm{~m}\end{array}$} & E1.3 & 6.8 \\
\hline & E2.3 & 48.8 \\
\hline
\end{tabular}




\subsection{Species richness of plant and non-timber forest products in the study area}

The analysis of species richness of tree species with circumference of greater than $94 \mathrm{~cm}$ was experimented in the sampling plot $40 \mathrm{x} 40 \mathrm{~m}$ which was named D1 while tree species with circumference of $32-93 \mathrm{~cm}$ in the sampling plot $20 \times 20 \mathrm{~m}$ was named D2. D3 is the sampling plot size of $10 \times 10 \mathrm{~m}$ which has tree circumference of $4-31 \mathrm{~cm}$ and D4 is the sampling plot size of $2 \times 2 \mathrm{~m}$ which has tree size with circumference of less $3 \mathrm{~cm}$. The result of the analysis is reported in tables 7-10 respectively.

Table 7 shows the species richness of the sampling plot size $40 \times 40 \mathrm{~m}$ with tree circumference of $94 \mathrm{~cm}$ and the analysis result indicates that dense forest with sea altitude ranges from 150-300 $\mathrm{m}$ has the highest value of species richness which varies from 2.73 to
3.25. While the species richness of the forest area with sea altitude ranges of $400-500 \mathrm{~m}$ are calculated at between 3.38 and 3.80, that of the forest area with sea altitude ranges of $600-700 \mathrm{~m}$ is very high with value of 4.61. In the secondary forest, species richness index is relatively low having the value of 0.00 and 0.72 compared to the secondary forest in high land area of D1 of 2.4 and 2.52.

Species richness of trees with circumference of 32 to $93 \mathrm{~cm}$ are examined in the sampling plot 20x20m (D2) and from the table 7, it shows that the primary forest has the lowest index of species richness (2.55) compared to the highest value (6.24) and this implies that the species richness is relatively high in the primary forest compared to the secondary forest $(1.92$ to 2.77 )

Table 7: Species richness of trees, plants and non-timber forest products

\begin{tabular}{|c|c|c|c|c|c|c|c|c|}
\hline \multirow[t]{2}{*}{ Sampling plots in forest } & \multicolumn{8}{|c|}{ Plot number and species richness } \\
\hline & $\begin{array}{l}\text { Plot } \\
\text { ID }\end{array}$ & D1 & $\begin{array}{l}\text { Plot } \\
\text { ID }\end{array}$ & D2 & $\begin{array}{l}\text { Plot } \\
\text { ID }\end{array}$ & D3 & $\begin{array}{l}\text { Plot } \\
\text { ID }\end{array}$ & D4 \\
\hline \multirow{2}{*}{$\begin{array}{l}\text { Zone 1: Pakxoun Village, sea } \\
\text { altitude ranges from } 150-200 \mathrm{~m}\end{array}$} & A1 & 3.25 & A1.1 & 4.24 & A1.2 & 4.60 & A1.3 & 0.76 \\
\hline & $\mathrm{A} 2$ & 0.91 & A2.1 & 2.77 & A2.2 & 4.12 & A2.3 & 2.19 \\
\hline \multirow{2}{*}{$\begin{array}{l}\text { Zone 2: Kenyong Village, sea } \\
\text { altitude ranges from } 300-400 \mathrm{~m}\end{array}$} & B1 & 2.73 & B1.1 & 2.55 & B1.2 & 3.10 & B1.3 & 2.82 \\
\hline & $\mathrm{B} 2$ & 00 & B2.1 & 2.06 & B2.2 & 3.07 & B2.3 & 2.73 \\
\hline \multirow{2}{*}{$\begin{array}{l}\text { Zone 3: Muangmouane Village, } \\
\text { sea altitude ranges from } 400-500 \mathrm{~m}\end{array}$} & $\mathrm{C} 1$ & 3.80 & C1.1 & 2.55 & $\mathrm{C} 1.2$ & 3.83 & C1.3 & 2.43 \\
\hline & $\mathrm{C} 2$ & 0.72 & $\mathrm{C} 2.1$ & 1.95 & $\mathrm{C} 2.2$ & 1.58 & $\mathrm{C} 2.3$ & 2.35 \\
\hline \multirow{2}{*}{$\begin{array}{l}\text { Zone 4: Phontan Village, sea } \\
\text { altitude ranges from 500-600m }\end{array}$} & D1 & 3.38 & D1.1 & 4.20 & D1.2 & 6.40 & D1.3 & 2.09 \\
\hline & D2 & 2.40 & D2.1 & 1.92 & D2.2 & 4.73 & D2.3 & 2.63 \\
\hline \multirow{2}{*}{$\begin{array}{l}\text { Zone 5: Napae Village, sea } \\
\text { altitude ranges } 600-700 \mathrm{~m}\end{array}$} & $\mathrm{E} 1$ & 4.61 & E1.1 & 3.41 & E1.2 & 3.82 & E1.3 & 1.82 \\
\hline & E2 & 2.52 & E2.1 & 2.08 & E2.2 & 4.68 & E2.3 & 1.33 \\
\hline
\end{tabular}

Species richness of the trees with circumference of 4 to $31 \mathrm{~cm}$ are examined in the sampling plot $10 \times 10 \mathrm{~m}$ (D3) and from the table 7, it shows that the primary forest has the lowest index of species richness (3.10) compared to the highest value (6.40 and this implies that the species richness is relatively high in the primary forest and are also high for the secondary forest (1.58 to 4.77$)$.

Species richness of the trees with circumference of less than $3 \mathrm{~cm}$ are examined in the sampling plot $2 \times 2 m$ (D4) and from the table 7, it shows that the primary forest has the lowest index of plant species richness (0.76) compared to the highest value (2.82) and this implies that the species richness is high and low.

\subsection{Assessment result of litter decomposition and soil strength}

The quadrat $1 \mathrm{x} 1$ meter established in the corner of the sampling plot $2 \times 2 \mathrm{~m}$ to collect the data on litter decomposition from branches, green and dry leaves and grasses. The result of the analysis are revealed in Table 8 as follows. 
Table 8: Litter decomposition of tree branches, green and dry leaves of quadrat 1xlm

\begin{tabular}{|c|c|c|c|c|c|c|c|}
\hline \multirow[t]{2}{*}{ Quadrat ID } & \multicolumn{3}{|c|}{ Type of decomposition (grams) } & \multicolumn{4}{|c|}{ Soil hardness } \\
\hline & Green & Dry & Mean & Spot 1 & Spot 2 & Spot 3 & Mean \\
\hline A1.4 & 500 & 900 & 700 & 3.8 & 3.2 & 3.5 & 3.50 \\
\hline $\mathrm{A} 2.4$ & 350 & 300 & 325 & 2.8 & 2.7 & 3.0 & 2.83 \\
\hline B1.4 & 300 & 590 & 445 & 3.4 & 4.1 & 3.2 & 3.56 \\
\hline B2.4 & 300 & 600 & 450 & 4.9 & 3.0 & 3.6 & 3.83 \\
\hline C1.4 & 350 & 580 & 465 & 2.9 & 4.1 & 3.2 & 3.40 \\
\hline $\mathrm{C} 2.4$ & 320 & 590 & 455 & 5.4 & 4.9 & 5.2 & 5.16 \\
\hline D1.4 & 450 & 560 & 505 & 5.3 & 4.3 & 5.6 & 5.06 \\
\hline D2.4 & 510 & 720 & 615 & 5.4 & 4.5 & 6.2 & 5.36 \\
\hline E1.4 & 490 & 480 & 485 & 4.9 & 5.3 & 3.8 & 4.66 \\
\hline E2.4 & 600 & 1200 & 900 & 6.3 & 4.4 & 7.0 & 5.90 \\
\hline$(A 1.4+A 2.4)$ & & & 512.5 & & & & 3.16 \\
\hline$(B 1.4+B 2.4)$ & & & 447.5 & & & & 3.69 \\
\hline$(C 1.4+C 2.4)$ & & & 460.0 & & & & 4.28 \\
\hline$(D 1.4+D 2.4)$ & & & 560.0 & & & & 5.21 \\
\hline$(E 1.4+E 1.4)$ & & & 692.5 & & & & 5.28 \\
\hline
\end{tabular}

Source: Fieldwork, 2014

From the analysis, it revealed that the smallest quantity of dry litter decomposition is 300 grams (A2.4) and the largest is 1200 grams (E1.4) while the smallest green litter decomposition is 300 grams (B1.4 and B2.4) and the largest is 600 grams (see Table 8).

From the analysis of soil hardness in the quadrat $2 \times 2$ $\mathrm{m}$, it indicates that the average least soil hardness is $5.90 \mathrm{~cm} / \mathrm{Kg}(\mathrm{E} 1.4)$ while the most soil hardness is $2.83 \mathrm{Cm} / \mathrm{Kg}$.

\subsection{Species density and richness of plant including Non-timber forest product in different forest zone}

From the analysis of the species density in sampling plot 40x40m, it reveals the lowest density is found in block (B2; RD1), which is $0 \%$; the medium density ranges bewteen $18.7 \%$ and $22.2 \%$ which is found in block (A1, B1; RD1). The highest density is from $66.6 \%$ to $75.0 \%$ which is found in block A2, C2, E2; RD1).

For the sampling plot 20x20m, it reveals the lowest density is found in block (A1.1, C1.1, D1.1, E2.1; RD2), where the plant species density stays between $13.0 \%$ and $17.9 \%$ and the medium density is bewteen $27.0 \%$ and $27.6 \%$ which is found in block (A2.1, E1.1; RD2). The highest density starts from $41.7 \%$ and $50.0 \%$ which is found in block (B1.1, B2.1, C2.1, D2.1; RD2).

The analysis on sampling plot $10 \times 10 \mathrm{~m}$ reveals that the lowest density is found in block (A1.2, A2.2, $\mathrm{C} 1.2$, D1.2, E2.2; RD3), which is between $8.6 \%$ and $19.0 \%$ while the medium density is approximately $22.2 \%$ which is found in block (D2.2; RD3). The highest density is from $30.6 \%$ to $35.3 \%$ which is found in block (B1.2, B2.2, C2.2, E1.2; RD3).

From the analysis of the species density in sampling plot $2 \times 2 \mathrm{~m}$, it reveals the lowest density is found in block (B1.3, B2.3, C1.3, C2.3, D1.3, D2.3, E1.3; d), which is between 2.3 and 7.5 while the medium density is 15.3 which is found in block (A2.3; d). The highest density is from 47.0 to 48.8 which is found in block (A1.3, E2.3; d).

The anlaysis on plant species richness of tree with circumference of more than $94 \mathrm{~cm}$ in the sampling plot $40 \times 40 \mathrm{~m}$ indicates that forest zone with sea altitude ranges of $150-300 \mathrm{~m}$ witnesses a tree richness of between 2.73 and 3.25, which is less than than forest zone with sea altitude ranges of 400$500 \mathrm{~m}$ that has value of 3.38 to 3.80 . The tree richness of forest zone with sea altitude ranges $600-700 \mathrm{~m}$ was found to be 4.61. In the secondary forest zone, the richness value is estimated to be lower for low and medium slopy area $(\mathrm{D} 1<1=0.0,0.72,0.91)$ compared to higher forest zone (D1>1=2.40, 2.52).

The anlaysis on tree richness of trees with circumference of $32-93 \mathrm{~cm}$ in the sampling plot $20 \times 20 \mathrm{~m}$ indicates that forest zone with sea altitude ranges of $150-300 \mathrm{~m}$ witnesses species richness of 3.41 , which is greater than than forest zone with sea altitude ranges of $400-500 \mathrm{~m}$ that has value of 2.55 . The species richness of forest zone with sea altitude ranges $600-700 \mathrm{~m}$ was found to be 6.24 . For the secondary forest zone in low, medium and high area, the richness value is estimated to between 1.92 and 2.77 .

The anlaysis on species richness of trees with circumference of $4-31 \mathrm{~cm}$ in the sampling plot 
$10 \times 10 \mathrm{~m}$ indicates that forest zone with sea altitude ranges of $150-300 \mathrm{~m}$, forest zone with sea altitude ranges of $400-500 \mathrm{~m}$, and high area with sea altitude ranges of $600-700 \mathrm{~m}$, the species richness value stay between 3.10 and 6.40. By contrast, for the secondary forest zone in low, medium and high area, the richness value is estimated to between 1.58 and 4.73 .

The anlaysis on species richness of tree with circumference of less than $3 \mathrm{~cm}$ in the sampling plot $2 \times 2 \mathrm{~m}$ indicates that forest zone with sea altitude ranges of $150-300 \mathrm{~m}$ has species richness value of 0.76 which is less than that of forest zone with sea altitude ranges of 400-500 m. However, in the high area with sea altitude ranges of $600-700 \mathrm{~m}$, the richness value is estimated to be between 1.82 and 2.82. For the secondary forest zone in low, medium and high area, species richness value is estimated to between 1.33 and 2.73 .

The comparision of litter decomposition in the sampling plot $2 \times 2 \mathrm{~m}$ indicates that the quadrat that has the smallest dry leaves is 300 grams (A2.4) and the largest plot contains about 1200 grams (E2.4). For the measurement of the green leaves, the smallest ammount is found in B1.4 and B2.4 which is about 300 grams each and the largest is E2.4 (600 grams). This implies that litter decomposition for dry and green leaves in forest zone with lower zone (150$200 \mathrm{~m}$ ) in sampling plot A1.4 consist of dry litter decomposition of 900 grams and green leaves of 500 grams. In higher forest zone of 600-700 m (E2.4), it consists of dry leaves of 1200 grams and green leaves of 600 grams. In forest zone of 300 to $500 \mathrm{~m}$ in sampling plot A1.4, ..D2.4, it consist of dry leaves of 300 to 500 grams and green leaves of 300 to 450 grams.

The comparision of soil hardness in the sampling plot $2 \times 2 \mathrm{~m}$ shows that the least average soil hardness is approximately $5.90 \mathrm{Cm} / \mathrm{Kg}$ (E1.4) and the highest value of soil hardness is $2.83 \mathrm{Cm} / \mathrm{Kg}$ (A2.4); and it reveals that the higher the forest zone, the lower the soil hardness respectively.

\section{Conclusion and Discussion}

The objectives of the paper are as follows.

- Assess species richness of plants, more precisely tree and non-timber forest products (NTFPs) in different altitudinal zones of Bolikhamxay Province

- Determine the density of plant and NTFPs in the study area, and

- To quantify the plant leaves and soil hardness measurement

We found that Shannon diversity index for the study area in the different forest zone of Bolikhamxay province was diverse in all sites. Approximately 55 tree species with circumference of greater than $94 \mathrm{~cm}$ were noticed in the sampling plot $40 \times 40 \mathrm{~m}$ compared to the total number of tree species with circumference of $32-93 \mathrm{~cm}$ is 43 plant species. We found 40 plant species in the sampling plot $10 \times 10 \mathrm{~m}$ when tree species has circumference of $4-31 \mathrm{~cm}$. For the sampling plot $2 \times 2 \mathrm{~m}$, the total number of tree species with circumference of less than $3 \mathrm{~cm}$ (height of 0.3 $1.5 \mathrm{~m})$ as well as the measurement of Non-timber forest products (NTFPs) is 43 plant species.

Overall, there were high variations in relative density, density, species richness, litter decomposition, and soil hardness.

It is noticeable that the higher the forest zone in this province, the lower the soil hardness. By contrast, the quantity of leaves litter was likely to increase in the higher forest zone.

\section{Acknowledgement}

The authors would like to thank very important valuable comments from Professors at the Faculty of Forest Science, National University of Laos. In addition, We would like thank Mr. Phanlone Keoviseth, Mr. Phokeo Khounnavong, staff of Bolikhamxay Provincial Office for Agriculture and Forestry, and anonymous reviewers of this paper.

\section{References}

1. Dalmayne, J., T. Möckel, et al. (2013). "Assessment of finescale plant species beta diversity using WorldView-2 satellite spectral dissimilarity." Ecological Informatics 18: 1-9.

2. Devi, U. and N. Behera (2003). "ASSESSMENT OF PLANT DIVERSITY IN RESPONSE TO FOREST DEGRADATION IN A TROPICAL DRY DECIDUOUS FOREST OF EASTERN GHATS IN ORISSA." Journal of Tropical Forest Science 15(1): 147-163.

3. Hayat, M. S. A., K. A. Kudus, et al. (2010). "Assessment of Plant Species Diversity at Pasir Tengkorak Forest Reserve, Langkawi Island, Malaysia." Journal of Agricultural Science 2(1).

4. Kent, M. and P. Coker (1992). Vegetation Description and Analysis: A Practical Approach. Chichester, John Wiley \& Sons.

5. Mittermeier, R. A., P. Robles-Gil, et al. (2004). Hotspots Revisited: Earth's Biologically Richest and Most Endangered Ecoregions. Mexico City, Mexico, CEMEX.

6. Peng, Y., M. Fan, et al. (2018). "Assessment of plant species diversity based on hyperspectral indices at a fine scale." Scientific Reports 8(1): 4776.

7. Phimmavong, S., B. Ozarska, et al. (2009). "Forest and plantation development in Laos: history, development and impact for rural communities." International Forestry Review 11(4): 501-513.

8. Stanisci, A., G. Pelino, et al. (2005). "Vascular plant diversity and climate change in the alpine belt of the central Apennines (Italy)." Biodiversity \& Conservation 14(6): 1301-1318.

9. Tagane, S., P. Souladeth, et al. (2018). "FLORA OF NAM KADING NATIONAL PROTECTED AREA II: 30 NEW RECORDS OF ANGIOSPERMS FOR LAOS." Edinburgh Journal of Botany 75(1): 107-116.

10. Zhu, H. (2017). "Floristic characteristics and affinities in Lao PDR, with a reference to the biogeography of the Indochina peninsula " PLoS ONE 12(6). 